\section{Net neutrality}

From mid-January 2010 to the final days of December, network (net) neutrality was an ongoing issue with an uncertain future. Yet, unlike in years past, some progress was made, setting the stage for Congressional action in the near future and a possible tugof-war between Congress and the Federal Communications Commission (FCC).

Back in January, ALA voiced support for the FCC's announcement of its efforts to maintain an open Internet by codifying the principles of network neutrality, including two new principles-nondiscrimination and transparency—introduced by FCC Chairman Julius Genachowski.

ALA believes nondiscrimination is essential to ensuring equal access to content on the Internet, and the principle of transparency will promote openness of service providers' practices, including how they manage their networks.

Yet, as is usually the case in Washington, reaching the next marker on the road to ensuring an open Internet took much time-about 12 months in this case.

Leading up to the FCC's vote on the net neutrality rule and order on December 21, ALA, Association of Research Libraries (ARL), and EDUCAUSE sent a letter to the commissioners stressing the importance of ensuring the upcoming net neutrality order contains sufficient protections for library and higher education services made available to the public. In the letter, the organizations specifically asked the FCC to address the following concerns prior to the scheduled vote on the net neutrality order.

- The definition of Broadband Internet Access Service should not be limited to consumer retail services. If the word consumer is defined as a residential consumer, then

Jenni Terry is press officer at ALA's Washington Office, e-mail: jterry@alawash.org libraries and higher education would not be protected by the proposed net neutrality rules and policies.

- ALA, ARL, and EDUCAUSE believe "paid prioritization" should be banned altogether. Higher education and libraries already pay subscriber fees to obtain access to the Internet. Our concern is that such prioritization puts not-for-profit educational institutions at a disadvantage compared to entertainment and for-profit educational entities.

- Net neutrality protections should be limited to "lawful traffic." Broadband operators should not be given absolute discretion to block traffic based on their own private determination that it is unlawful.

- Wireless services should be treated the same as wireline services. All Internet subscribers, whether using wireline or wireless technologies, should have the same right to a neutral, nonprioritized Internet.

On December 21, the FCC voted (3-2) in favor of the net neutrality order. However, from ALA's perspective, the order does not go far enough to ensure libraries and other community anchor institutions' content and services can be equally accessed by the public.

While the FCC addressed the definition issue raised in a letter by U.S. Reps. Doris Matsui (CA-5), Edward Markey (MA-7) and Anna Eshoo (CA-14) on behalf of the ALA, the additional provisions ALA sought (bullets 2-4 above) were not sufficiently met.

The order does not hold wireless to the same nondiscriminatory standards as wireline access, despite the growing number of libraries, higher education institutions, and users that use wireless technology to access content and information. Additionally, the practice of paid-prioritization must be banned to protect libraries and educational interests from being charged more to provide

(continues on page 112) 
and subtitles are included where appropriate. Even relatively large maps load quickly and can be opened in full size with a left click.

The quality of images was generally high, though occasionally some minor "noise" was visible. Some maps were still hard to read clearly, even when viewing at maximum size, perhaps reflecting the limitations of the original print versions.

An easily found FAQ page indicates that most of PCL's online maps are in the public domain, and those that are not are clearly labeled as copyrighted materials. PCL requests credit for reuse of maps from the site. The FAQ includes advice for viewing and printing online maps, information on use of the print collection, and links to other discovery sites and places to purchase maps. PCL is an extensive, online collection for both current and historical maps. Users will find it a convenient and robust alternative to print map collections and commercial map sites, particularly when using the site search box.

Users expecting interactive, dynamic maps will find only static maps within the PCL collection, but will be presented with numerous links to a wide and representative selection of the best map resources on the Web. PCL is updated frequently._-Jeremy Donald, Trinity University, jdonald@trinity.edu

World Bank. Access: http://www.worldbank.

org/.

Nine tabbed links on the homepage of the World Bank Web site direct users to statistical data, project descriptions, country information, publications, news, and a comprehensive statement of the bank's aims and objectives.

Describing itself as "a vital source of financial and technical assistance to developing countries around the world," World Bank serves up extensive information for an audience that includes journalists, students, job seekers, and potential investors.

Although World Bank's working language is English, the Web page can be viewed in multiple languages. In addition to English, French, and Spanish, parts of the Web site may be viewed in Arabic, Chinese, Russian, Vietnamese, and other languages.

The "Data" and the "Projects and Operations" tabs lead to two of the most substantial and potentially useful sections of the site. The "Data" tab provides detailed economic, demographic, and health data for more than 200 countries. From this tab, clicking on "Data Catalog" provides access to more than 2,000 indicators from the World Bank datasets. This information is available for simple downloads to Excel or CSV files. For more sophisticated users, customizable queries and the creation of charts from the data is possible. The "Projects and Operations" tab is the gateway to expanded information on the bank's projects in various countries. One can search a country and or region to determine active or closed projects and their approval dates. The data can be exported to Excel or XML.

Librarians and library users will appreciate the "Publications and Documents" section of the Web site. According to data on the site, there are more than 80,000 free downloadable documents available in full text and in PDF.

There is also an online World Bank Library that requires a subscription.

Overall, the site is relatively easy to navigate, but there are sections that are more difficult to maneuver and the information presented is not always easy to find. The strength of the site is the wide variety of unique information it provides.-Maureen James, University of Arkansas-Little Rock, mejames@ualr.edu n

\section{("Washington Hotline ..." cont. from page 108)}

the public with the same quality of access to their educational and nonprofit content.

Moving forward, the ALA will look to the FCC to address these additional concerns and to provide long-term oversight and enforcement of the rule. In addition, ALA is preparing for significant Congressional activity on net neutrality as two bills seeking to prohibit the FCC from regulating the Internet have already been introduced, H.R. 96 and H.R. 166. 